\title{
Nimesulide and Celecoxib Inhibits Multiple Oncogenic Pathways in Gastric Cancer Cells
}

\author{
Jayaprakash Periasamy ${ }^{1}$, Muthulakshmi Muthuswami ${ }^{1}$, Vignesh Ramesh ${ }^{1}$, Thangaselvam Muthusamy ${ }^{1}$, Amrita Jain ${ }^{1}$, Chandrabose \\ Karthikeyan ${ }^{2}$, Piyush Trivedi ${ }^{2}$, Rayala Suresh Kumar ${ }^{3}$, Paramasamy Gunasekaran ${ }^{1}$, Sun Young Rha ${ }^{4}$, Partick Tan ${ }^{5}$ and Ganesan
} Kumaresan ${ }^{1 *}$

${ }^{1}$ Cancer Genetics Laboratory, Department of Genetics, Centre for Excellence in Genomic Sciences, School of Biological Sciences, Madurai Kamaraj University, Madurai, India ${ }^{2}$ School of Pharmaceutical Sciences, Rajiv Gandhi Proudyogiki Viswavidyalaya, University of Technology of Madhya Pradesh, Gandhi Nagar, Bhopal, India ${ }^{3}$ Department of Biotechnology, Indian Institute of Technology Madras (IITM), Chennai, India

${ }^{4}$ Department of Internal Medicine, Yonsei Cancer Centre, Yonsei University College of Medicine, Seoul, South Korea

${ }^{5}$ Duke-NUS Graduate Medical School Singapore, 8 College Road, Singapore

\begin{abstract}
Despite being the leading cause of cancer death, targeted therapy for gastric cancer is yet to be established. Wnt/ $\beta$-catenin signaling is highly deregulated in cancers of gastrointestinal origin including gastric cancers. Stabilization and deregulation of $\beta$-catenin occurs at multiple levels and so is being needed to identify a spectrum of Wnt inhibitors to combat deregulated Wnt signaling at the level of various targets and also in different combinations. We developed a luciferase reporter based gastric cancer cellular assay system for Wnt pathway modulator screening and identified nimesulide, a known COX-2 inhibitor as an inhibitor of Wnt/ $\beta$ catenin signaling pathway. Comprehensive signaling pathway profiling revealed that nimesulide could inhibit STAT3, IRF1 and RXR signaling apart from inhibiting Wnt/ $\beta$-catenin-Myc-E2F signaling cascade. Nimesulide elicits a strong anti-proliferative effect by promoting cell cycle arrest in multiple gastric cancer cell lines. Inhibition of Wnt and STAT3 signaling are found to be COX-2 independent, while the inhibition of RXR and IRF1 pathways are due to the COX-2 inhibiting feature of nimesulide. While nimesulide is capable of activating Notch signaling in gastric cancer cells, celecoxib inhibits Wnt, Myc, E2F, RXR, STAT3, MAPK and Notch signaling pathways in gastric cancer cells. Signaling pathway focused analysis of gastric cancer transcriptome revealed that Wnt, STAT3, IRF1 and RXR signaling pathways are highly deregulated in majority of gastric tumors and indicates the potential of nimesulide and celecoxib class of drugs for targeted gastric cancer therapeutics. The differential inhibition of multiple signaling by nimesulide and celecoxib deserve further investigation.
\end{abstract}

Keywords: Celecoxib; COX2; Gastric cancer therapeutics; Nimesulide; NSAID; Wnt $/ \beta$-catenin signaling

\begin{abstract}
Abbreviations: COX-2: Cyclooxygenase-2; ERK/MAPK: Extracellular Signal-Regulated Kinase Regulated Mitogen-Activated Protein Kinase Signaling; GEO: Gene Expression Omnibus; MSigDB: Molecular Signatures Database; NSAID: Non-Steroidal Anti Inflammatory Drug; PGE2: Prostaglandin E2; RT-PCR: Reverse Transcription Polymerase Chain Reaction; RXR: Retinoid X Receptor; STAT3: Signal Transducer and Activator of Transcription 3
\end{abstract}

\section{Introduction}

Stomach cancer is the second leading cause of global cancer mortality and estimated as fourth common cancer worldwide $[1,2]$. Deregulation in the growth signaling pathways due to genetic alterations often persuades normal cells to undergo transformation and cancer development [3]. Among the deregulated signaling, Wnt $/ \beta$ catenin signaling plays a predominant role in gastric tumorigenesis and the recent pathway focused investigation of gastric cancer transcriptome has shown the deregulation of $\mathrm{Wnt} / \beta$-catenin signaling in $46 \%$ of patients [4]. Several members of $\mathrm{Wnt} / \beta$-catenin pathway like $A P C, C D H 1, C T N N B 1$ and AXIN2 [5-7] are often mutated and being the primary causative factors which makes the $\beta$-catenin nonresponsive to APC/AXIN2/GSK-3 $\beta$ destruction complex. This results in cytosolic stabilization and nuclear accumulation of $\beta$-catenin and drives transcriptional activation of Wnt target genes [8]. Apart from its own activation, increasing evidences show that Wnt signaling involves in molecular conversation with other oncogenic counterparts such as MAPK, PI3K/AKT, STAT3 and Hedgehog [9-12] and potentiates cancer growth. Due to its key role in tumorigenesis, Wnt/ $\beta$-catenin signaling is recognized as an attractive target for anticancer drug development [13]. However, none of the identified Wnt pathway specific inhibitors have reached clinical trials and hence Wnt pathway based targeted therapy is lagging behind [14]. Many of the earlier Wnt $/ \beta$-catenin signaling modulator screening methods involved noncancerous cells [15] where there is a possibility that identified inhibitors acting upstream of $\beta$-catenin may not be effective in targeting Wnt signaling in cancer cells with defect(s) in pathway component genes like $\beta$-catenin. Therefore, the discovery of inhibitors which act around the stabilized $\beta$-catenin through the disruption of transcriptional response would facilitate prominent targeted therapeutic effect in wide range of tumors and such specific screening systems are largely lacking.

Some of the clinically practiced drugs, such as nonsteroidal antiinflammatory drugs (NSAIDs) [13], analgesics and antibacterial agents [16], have been identified as inhibitors of Wnt signaling. NSAIDs are preferentially cyclooxygenase (1/2) inhibitors, work through suppression of inflammation mediated by prostaglandin.

*Corresponding author: Ganesan Kumaresan, Department of Genetics, School o Biological Sciences, Madurai Kamaraj University, Madurai-625021, India, Tel: +91 452 2456224; Fax: +91 452 2456433; E-mail: kumar@oncocellomics.org

Received January 13, 2013; Accepted March 12, 2013; Published March 15 2013

Citation: Periasamy J, Muthuswami M, Ramesh V, Muthusamy T, Jain A, et al (2013) Nimesulide and Celecoxib Inhibits Multiple Oncogenic Pathways in Gastric Cancer Cells. J Cancer Sci Ther 5: 126-136. doi:10.4172/1948-5956.1000198

Copyright: @ 2013 Periasamy J, et al. This is an open-access article distributed under the terms of the Creative Commons Attribution License, which permits unrestricted use, distribution, and reproduction in any medium, provided the original author and source are credited. 
NSAIDs with distinct structures like aspirin, indomethacin, ibuprofen, sulindac exhibit considerable interest as anticancer agents. Indeed, many epidemiological studies have highlighted the chemopreventive effect of aspirin and other NSAIDs upon regular use by reducing the incidence and severity of human cancers $[17,18]$. Aspirin and celecoxib have become potent inhibitors of constitutive Wnt signaling and able to reduce the polyp formation, tumorigenesis and elicits anti tumor response in many cancers including gastric cancer [17,19-22]. Overexpression of COX-2 is frequently observed in gastric cancer with $\sim 50$ $\%$ frequency and is also associated with lymphatic metastasis and poor prognosis [23,24]. Indeed, COX-2 gene expression in gastric cancer cells is also regulated by $\mathrm{Wnt} / \beta$-catenin signaling [25]. Therefore identification of inhibitors which promotes blockade of Wnt and COX-2 activity in gastric cancer cells would pave way for developing targeted therapeutics for clinical management of gastric cancer. In order to identify potential inhibitors for deregulated and constitutive Wnt transcriptional response, we established a cell based assay system with stably maintained TCF responsive genetic reporter system in a gastric cancer cell line with constitutive Wnt signaling owing to mutant $\beta$-catenin. Nimesulide, one of the COX-2 inhibitors has been identified as Wnt inhibitor through screening a panel of drugs and further investigated its Wnt dependent/independent and COX-2 dependent/ independent effects on multiple oncogenic signaling pathways in gastric cancer cell lines in an unbiased manner. This investigation reveals the possible therapeutic repositioning candidacy of nimesulide derivatives and celecoxib for the development of gastric cancer therapeutics.

\section{Materials and Methods}

\section{Cell lines and culture}

The human gastric cancer cell line AGS was obtained from National Centre for Cell Science (NCCS), Pune, India. Kato-III was obtained from ATCC, USA, and MKN45 cells were from Japan Health Science Research Resource Bank. Gastric cancer cell lines YCC3 and YCC16 cell lines were kind gift from Dr. Sun Young Rha, Yonsei Cancer Centre, Korea. AGS cell line was cultured in Dulbecco's Modified Eagle Medium / Nutrient mixture F-12 Ham (HiMedia, India) supplemented with $10 \%$ Fetal bovine serum (Sigma), Kato-III was cultured in RPMI1460 (HiMedia, India) supplemented with 20\% FBS, MKN45 cells in RPMI-1640 with 10\% FBS and YCC3, YCC16 cell lines were propagated in MEM (HiMedia, India) with 10\% FBS under standard cell culture conditions. All the cell culture flasks, multi-well plates and dishes were from Corning. The cell lines were authenticated by Affymetix 500K SNP profiling, genome-wide mRNA profiling using Affymetrix HG133A chips and cell line specific candidate gene expression analysis.

\section{Chemicals and reagents}

Small chemical library used in the screening is a collection from Dr. Piyush Trivedi, RGPV, Bhopal, India. The compounds of the library were dissolved in $100 \%$ DMSO and maintained as $10 \mathrm{mM}$ stock. Nimesulide, celecoxib, lithium chloride, IWR-1, PNU-7465 and PGE2 were from Sigma. 45 Signaling pathway reporter plasmid panel (CCA901L) was from SA Biosciences. TOPflash (TCF reporter plasmid) from Millipore, pGL4.73 [hRluc/SV40] and pGL4.27 [luc2P/minP/ Hygro] from Promega were used for the experiments.

\section{Transfection and selection of stable transfectants}

Gastric cancer cells were transfected with the specified plasmids using the FuGENE HD transfection reagent (Promega), as per the recommended standard protocol. The transfections were carried out in 6 well cell culture plates for the gene expression analysis and western blotting experiments. All the transfections were performed in 24 well cell culture plates for reporter assays except the primary screening which was performed in a 96 well cell culture plates. CTNNB1 siRNA and non-targeting control siRNA (Dharmacon) was transfected in the multi-well cell culture plates using Oligofectamine reagent (Invitrogen) as per the manufacturer's standard protocol. pWNT-luciferase plasmid (SA Biosciences) harboring hygromycin resistance was transfected in AGS cells and 48 hours later, cells were selected with $200 \mu \mathrm{g} / \mathrm{ml}$ of hygromycin B and the stable pools were further expanded.

\section{Cytotoxicity and cell proliferation assay}

Dose dependent cytotoxicity and time-course cell proliferation assays were performed in 96 well cell culture plates. After the treatment time points, MTT reagent was added to the wells (Bio Basic Inc) and incubated for 4 hours. Subsequently, formazan was dissolved in DMSO and measured calorimetrically at $570 \mathrm{~nm}$. Optical density in comparison to the control cells were measured and plotted as cell viability.

\section{Pathway profiling in gastric cancer cell lines by Cignal 45 pathway reporter array}

Gastric cancer cell lines were seeded in 96 well cell culture plates and transfected with Cignal 45 pathway reporter array panel of plasmids (SA Biosciences). The plasmids used for 45 signaling pathways are: pSTAT3-FLUC, pIRF1-FLUC, pRXR-FLUC, pWnt-FLUC, pE2F1/ DP1-FLUC, pMyc/Max-FLUC, pATF4/3/2-FLUC, pAndrogen Receptor-FLUC, pNrf2 \& Nrf1-FLUC, pATF6-FLUC, pC/EBP-FLUC, pCREB-FLUC, pE2F/DP1-FLUC, pP53-FLUC, pEGR1-FLUC, pCBF/ NF-Y/YY1-FLUC, pEstrogen Receptor (ER)-FLUC, pGATA-FLUC, pGlucocorticoid Receptor(GR)-FLUC, pHSF-FLUC, pHNF4-FLUC, pMTF1-FLUC, pGLI-FLUC, pHypoxia-inducible factor-1(HIF-1)FLUC,pSTAT1/STAT2-FLUC, pSTAT1/STAT1-FLUC, pKLF4FLUC, pLXRa-FLUC, pElk-1/SRF(ERK/MAPK)-FLUC,pAP-1(JNK/ MAPK)-FLUC, pMEF2-FLUC, pNanog-FLUC, pNFkB-FLUC, pRBP-Jk-FLUC, pOct4-FLUC, pPax6-FLUC, pFOXO-FLUC, pNFATFLUC, pPPAR-FLUC, pProgesterone Receptor-FLUC, pRetinoic Acid Receptor(RAR)-FLUC, pSox2-FLUC, pSP1-FLUC, pSMAD2/3/4FLUC, pVitamin-D Receptor-FLUC, AhR-FLUC, CMV-FLUC and CMV-Renilla. In each well, a pathway specific reporter plasmid was transfected along with renilla luciferase internal control plasmid (CMV-RLUC) at 100:1 ratio. $24 \mathrm{Hrs}$ after transfection, cells were treated with drugs and incubated for 24 hours and then dual luciferase assays were performed. For luciferase reporter assays, the cells were lysed with 1X passive lysis buffer (Promega) and the luciferase activity assay was performed by dual-luciferase reporter assay protocol as described [26] using luciferin (Life Science Technologies) and Coelenterazine (Gold Biotechnology). Firefly and Renilla luciferase activities were measured in Spectramax L microplate luminometer (Molecular Devices).

\section{Antibodies and Western blotting}

Gastric cancer cells treated with nimesulide were subjected to protein extraction and western blotting. Specific antibodies were used for the detection of cellular levels of $\beta$-catenin (219353, CalBiochem), CyclinD1 (SC-8396, Santa Cruz Biotechnology), c-Myc (SC-40, Santa Cruz Biotechnology), APC (SC-9998, Santa Cruz Biotechnology), GSK3 $\beta$ (SC-9166) and phospho-GSK3 $\beta$ (SC-11757, Santa Cruz Biotechnology). Celecoxib treated cell lysates were probed with $\mathrm{p} 42 / 44$ MAPK antibody (\#9107, Cell signaling) and phospho-p42/44 MAPK antibody (\#9106, Cell signaling) for the analysis of MAPK regulation. Anti- $\beta$-actin (\#A1978, Sigma) and Anti-Vinculin (sc-25336, Santa cruz biotechnology) antibodies were used to detect internal control proteins $\beta$-actin and vinculin. Bolts were developed using Western Lightning Plus-ECL, chemiluminescence substrate (PerkinElmer). 


\section{PGE2 treatment and RT-PCR}

Gastric cancer cell lines were seeded in 24 well plates and maintained in serum deprived conditions for 24 hours. Subsequently, the cells were transfected with signaling pathway specific firefly reporter plasmids (pSTAT3-FLUC, pIRF1-FLUC, pRXR-FLUC, pWnt-FLUC, pCREB-FLUC) along with CMV-RLUC renilla luciferase reporter plasmid at 100:1 ratio. $24 \mathrm{Hrs}$ later, the cells were treated with varying concentrations of PGE2 and assayed by dual luciferase assay upon 12 hours of incubation.

AGS cells seeded in 6 well culture plate were treated with increasing concentration of nimesulide and celecoxib and incubated for 48 hours. Subsequently, total RNA was extracted using Trizol (Invitrogen) and cDNA was synthesized from the isolated RNA using Reverse Transcriptase (Invitrogen) as per the standard protocol. cDNA was used for further semi-quantitative RT-PCR experiments to analyze the relative gene expression using gene specific primers.

\section{Cell cycle analysis by flow-cytometry}

For cell cycle analysis, cell lines were treated with drugs and stained with Propidium Iodide (BD Biosciences) and analyzed in the flowcytometry. The staining procedures for cell cycle analysis were followed according to manufacturer's instructions. FlowJo software was used for data analysis.

\section{Signature based pathway activation in primary gastric tumor microarray data}

Gene expression profile data for independent gastric cancer cohorts were obtained from GEO database. Pathway specific gene signatures used in this study were obtained from MSigDB database (http://www.broad.mit.edu/gsea/msigdb/genesets) and from research articles. Details of the signatures and their sources are available in supplementary table S2. Each signature is represented by a gene set and termed as query signature (QS). Depending on the signature, a QS may consist of up and / or down- regulated genes, i.e. genes up or down regulated upon the activation of the specific signaling pathway. Scoring of pathway activation in gastric tumors was performed from the gene expression profile of the tumors, based on gene signature enrichment analysis. Gene signature based pathway activation prediction method described previously was followed [27].

\section{Statistical Analysis}

The experiments carried out in the study were triplicates and data represented as mean \pm SEM. Statistical comparison of values were made using two-tailed Student's $t$ test, and statistical significance was considered to be present when $P<0.05$.

\section{Results}

\section{Nimesulide inhibits $W n t / \beta$-catenin signaling and promotes} growth arrest in gastric cancer cells

Identification of potential Wnt inhibitors is the prime step in the development of therapeutics against $\mathrm{Wnt} / \beta$-catenin activated gastric cancers. For the screening and identification of $\mathrm{Wnt} / \beta$-catenin inhibitors, AGS-pWnt-luc reporter stable cells were generated by transfecting pWnt-luc, luciferase reporter plasmid in AGS cell line (Wnt/ $\beta$-catenin hyperactive cells) and selecting stable cells with hygromycin-B. AGS-pWnt-luc reporter stable cells were evaluated by modulating Wnt/ $\beta$-catenin signaling by i) GSK3 $\beta$ inhibitor (Wnt activator) Lithium chloride, ii) Wnt inhibitor Diclofenac and iii) CTNNB1 knockdown, which all significantly altered the Wnt reporter activity (Figure 1A).
Subsequently, Wnt inhibitor screening was performed with a small compound library using AGS-pWnt-luc reporter cells. Luciferase reporter activity was normalized with cell viability assay and compounds that modulated the Wnt reporter activity above 2 folds were further screened (Figure 1B and Supplementary Table S1). One of the compounds, nimesulide was consistent in inhibiting TCF reporter activity in multiple independent assays and also evoked dose dependent response. Inhibition of TCF reporter activity $(P=0.0005)$ was further confirmed by transient dual reporter assay by normalizing the activity of firefly luciferase with renilla luciferase (Figure $1 \mathrm{C}$ and Supplementary Figure S1A). Thus Wnt/ $\beta$-catenin pathway modulator screening reporter system is established in gastric cancer cell line, and a novel Wnt inhibition potential of nimesulide has been identified from the initial screening. To functionally evaluate the effect of nimesulide on cell viability and proliferation in gastric cancer cells, MTT assay was performed and shows inhibition in cell viability at higher concentrations in AGS cells (Figure 1D). Further, nimesulide elicits strong growth inhibition in multiple gastric cancer cell lines at the identified effective dose of Wnt inhibition $(100 \mu \mathrm{M})$ (Figure 1E).

\section{Nimesulide stabilizes APC/GSK3 $\beta$ destruction complex and promotes degradation of $\beta$-catenin}

Cell cycle phase analysis upon nimesulide treatment $(100 \mu \mathrm{M})$ shows significant reduction in $S$-phase population $(P=0.02)$ and elevation of G1-populations which is an indication of G1-S phase arrest (Figure 2A) and this is associated with down-regulation of E2F1 reporter activity $(P=0.04)$ and Myc reporter activity $(P=0.05)$ (Figures $2 \mathrm{~B}$ and $2 \mathrm{C}$ ). Thus nimesulide promotes growth arrest in gastric cancer cells through the inhibition of E2F1 dependent cell cycle progression. To investigate the mechanism of inhibition of Wnt signaling and G1-S phase arrest by nimesulide, panel of gastric cancer cells with high $\beta$-catenin expression such as AGS, Kato-III, and MKN45 were investigated for the effect of nimesulide treatment in cellular $\beta$-catenin levels and target protein c-Myc and CyclinD1 expression. AGS, KatoIII and MKN45 cells were treated with increasing concentrations of nimesulide for 24 hours and the expression of proteins were analyzed by western blotting. Interestingly, $\beta$-catenin level is reduced at the increasing concentrations of nimesulide in all the cell lines along with the down-regulation CyclinD1. c-Myc was found down-regulated in AGS and MKN45 cells (Figure 2D and Supplementary Figure S1B). CyclinD1 is a positive regulator of E2F1 mediated progression of G1-S transition [28] and thus the $\beta$-catenin dependent down-regulation of CyclinD1 by nimesulide treatment is the underlying mechanism of growth arrest in gastric cancer cells. To address the mode of $\beta$-catenin protein reduction by nimesulide, the activation of APC/GSK3 $\beta$ destruction complex was suspected and investigated. AGS, Kato-III and MKN45 cells were treated with nimesulide and the expression of APC, GSK3- $\beta$ and phospho-GSK3- $\beta$ (ser9) were analyzed. Nimesulide treatment increased APC protein level and promotes activation of GSK3 $\beta$ by reducing inactivating phosphorylation at serine- 9 residue in multiple Wnt activated gastric cancer cell lines (Figure $2 \mathrm{E}$ and Supplementary Figure S1C). These results show that nimesulide inhibits Wnt $/ \beta$-catenin signaling through APC/GSK3 $\beta$ mediated destruction of $\beta$-catenin, which also results in the inhibition of $\mathrm{Myc} / \mathrm{E} 2 \mathrm{~F} 1$ mediated transcription and G1-S transition.

\section{Nimesuide inhibits $W n t / \beta$-catenin signaling through $\mathrm{COX}-2$ independent mechanism}

It is known that COX- 2 regulates $\mathrm{Wnt} / \beta$-catenin signaling by positive feed-back loop in cancer cells through prostaglandin E2 (PGE2) [29], and hence we initially hypothesized COX-2 dependency 
A

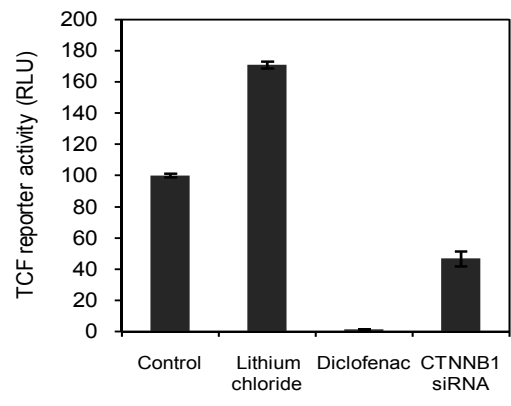

B

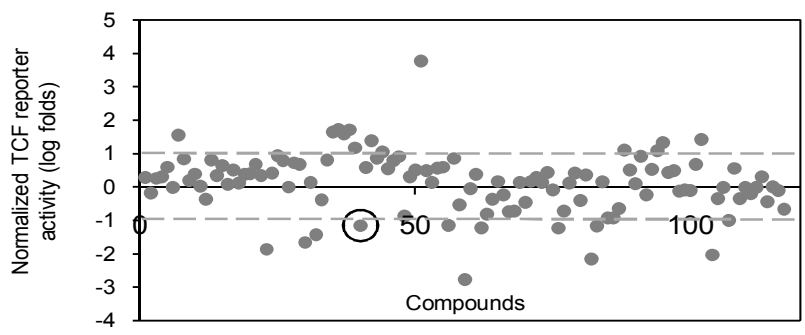

C

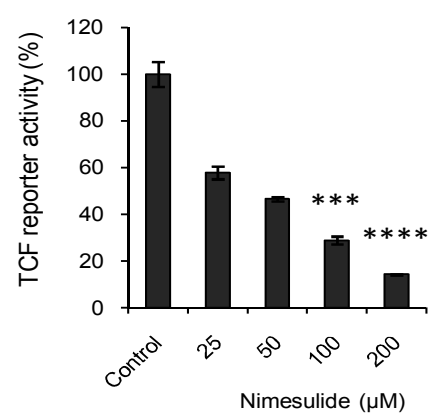

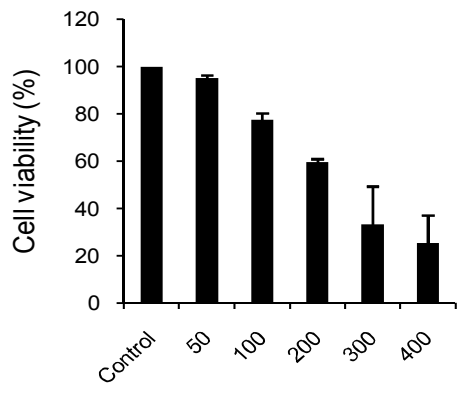

$\mathbf{E}$

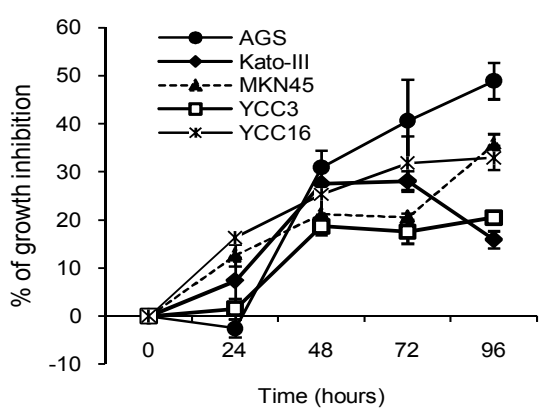

Figure 1: Identification of nimesulide as inhibitor of activated Wnt/ $\beta$-catenin signaling and gastric cancer cell proliferation. A) Validation of the authenticity of AGS-Wnt reporter cell line through genetic and chemical modulations of intrinsic Wnt/ $\beta$-catenin pathway activity. B) Screening of a compound library in AGS-Wnt reporter stable cell line identifies Wnt inhibitory effect of Nimesulide (circled one also confirmed by secondary screen). C)Transient TCF reporter assay showing the inhibition of Wnt activity by nimesulide in a dose dependent manner in AGS cells. D) Dose dependent inhibition of cell viability by nimesulide in AGS cells at 48 hours of treatment (MTT assay). E) Proliferation pattern of gastric cancer cell lines upon nimesulide $(100 \mu \mathrm{M})$ treatment measured by MTT assay $\left({ }^{* * *} P=<0.001,{ }^{* * *+} P=<0.0001\right)$.

in Wnt/ $\beta$-catenin signaling inhibition by nimesulide. Presumably, inhibition of COX-2 by nimesulide could lead to the blockade of PGE2 (the product of COX-2) which in turn might inhibit Wnt activation loop. By comparing TCF reporter activity and PTGS2 gene expression across a panel of gastric cancer cell lines, Kato-III was identified as a Wnt activated but COX- 2 negative cell line and AGS cell line as Wnt activated and COX-2 expressing cell line (Figure 3A). Initially, the existence of COX-2 mediated Wnt activation loop was evaluated by exogenous PGE2 treatment followed TCF and CREB reporter assay in AGS cells. PGE2 treatment results in activation of TCF reporter activity in dose dependent manner and shows COX-2 responsive Wnt signaling (Figure 3B). CREB reporter was used as positive control as CREB can be activated by PGE2 [30]. Subsequently, we asked whether nimesulide inhibits Wnt signaling even in the presence of PGE2 to look for the possibility of COX-2 independency. In AGS cells, upon treating nimesulide at increasing concentrations along with constant level of PGE2 $(32 \mu \mathrm{M})$, a significant down-regulation of TCF activity irrespective of PGE2 treatment was observed (Figure 3C). Further, in Kato-III cells (COX-2 non expressive), TCF activity was nonresponsive to PGE2 (Figure 3D). On the other hand, nimesulide inhibits Wnt signaling by reducing $\beta$-catenin level (Figure 2D) and the concomitant down-regulation of TCF reporter activity in Kato-III cells (Figure 3E). All these suggest that inhibition of Wnt signaling by nimesulide is independent of its COX-2 inhibiting capability in gastric cancer cells.

\section{Nimesulide modulates cellular STAT3, IRF1 and RXR response in gastric cancer cells}

To investigate the other possible pathway modulatory effects in global scale, we performed a multi-signaling pathway profiling upon nimesulide treatment $(100 \mu \mathrm{M})$ in AGS cells (Figure 4A). This comprehensive pathway profiling comprises luciferase based reporter assays for a panel of 45 distinct cellular genomic signaling responses. Upon nimesulide treatment, the pathways which consistently showed more than 2 folds up/down-regulations were taken for further analysis. Interferon Regulatory factor-1 (IRF-1), Retinoic acid X Receptor (RXR) and Signal Transducer and Activator of Transcription 3 (STAT3) responsive reporter activities were consistently and significantly down regulated ( $P=0.01$ (RXR), 0.004 (IRF1), 0.05 (STAT3)) by nimesulide in AGS cells. IRF1 is interferon stimulated transcription factor and RXR is retinoic acid regulated nuclear receptor acts as transcriptional co-activator/repressor which controls cell growth and survival [31,32]. STAT3 signaling known to promote aggressiveness in gastric cancer [33] is also modulated by nimesulide. Furthermore, nimesulide consistently inhibited IRF1, RXR and STAT3 pathways along with Wnt signaling in three different gastric cancer cell lines AGS, YCC3 and MKN45 (Figures 4B-D). In AGS cells, nimesulide reduces the expression of known IRF1 regulated genes IFI27 and IFI44 along with RXR signaling target gene NEDD9 (Figure 4E). This is the first report showing modulation of IRF1 and RXR signaling by nimesulide which all results in the concomitant inhibition of gastric cancer cell proliferation.

\section{Nimesulide modulates STAT3/IRF1/RXR signals through COX-2 dependent and independent mechanisms}

The regulation of IRF1, STAT3 and RXR signaling in gastric cancer is poorly understood. To delineate the mode of IRF1, RXR and STAT3 pathway modulations, $\mathrm{Wnt} / \beta$-catenin and COX-2 pathways were modulated independently and looked for the impact on IRF1, STAT3 
A
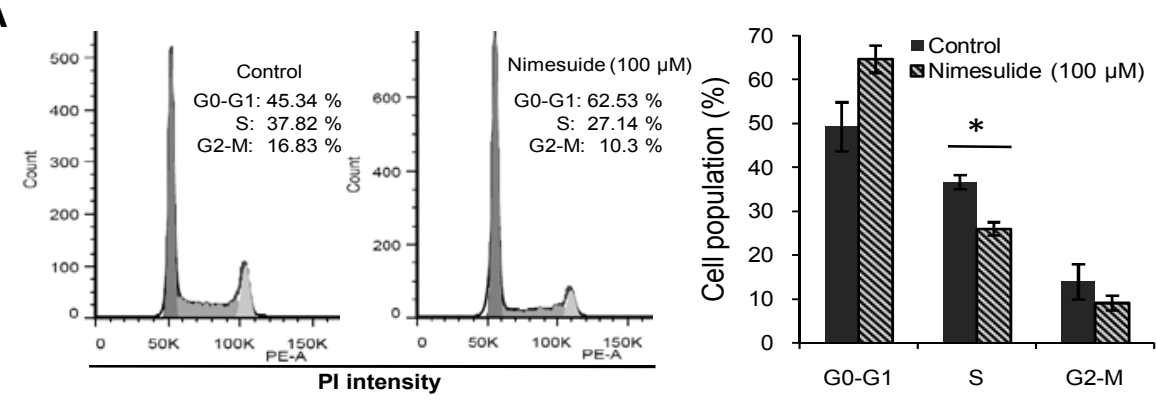

B

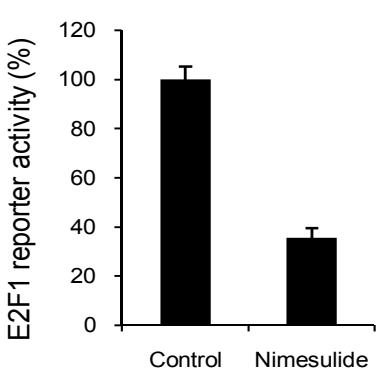

C

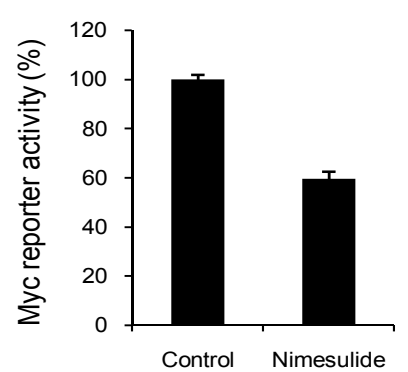

D

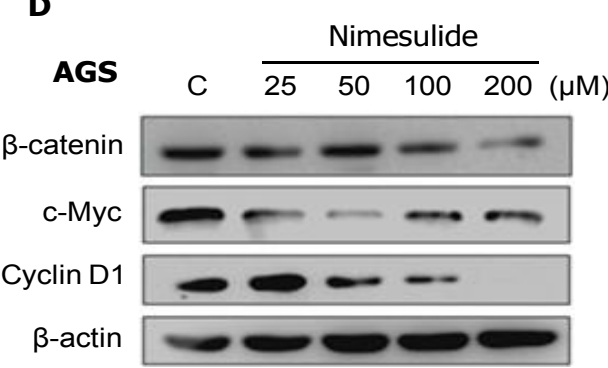

E
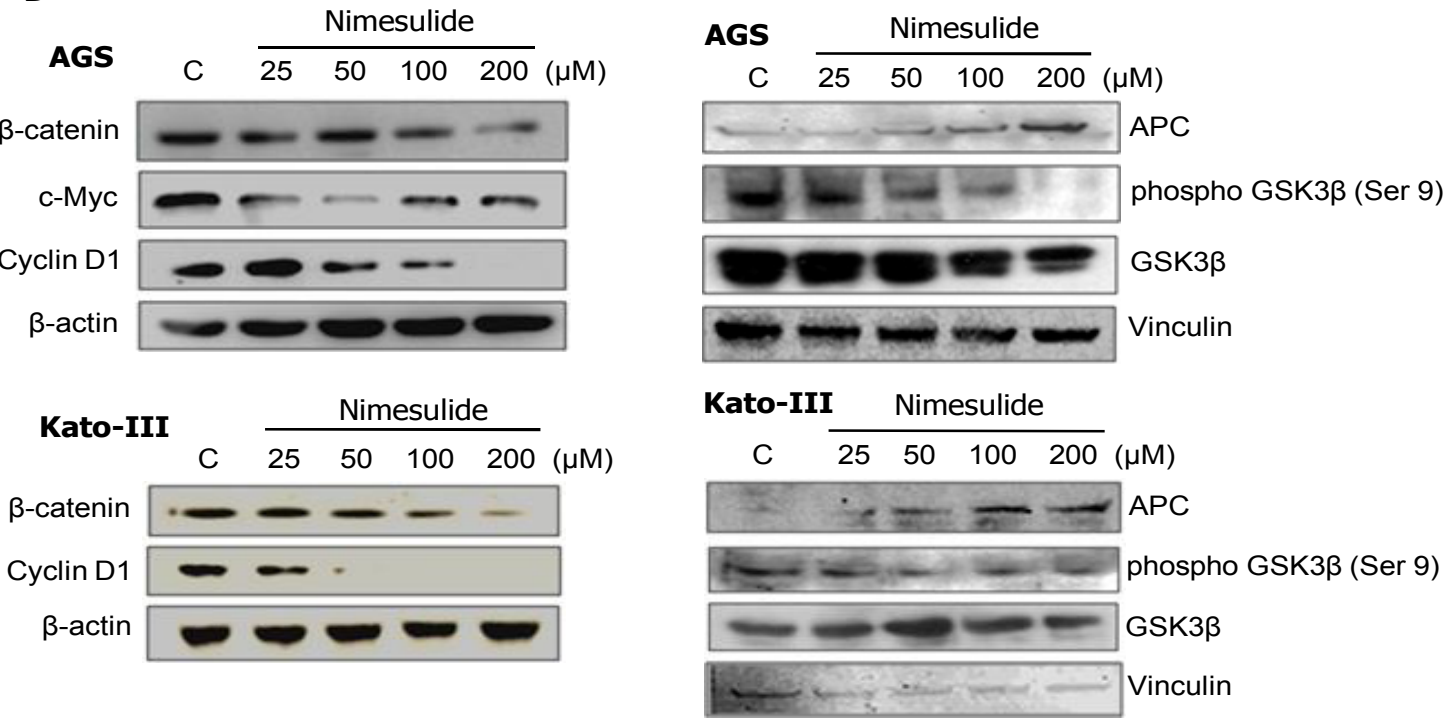

Figure 2: Nimesulide promotes cell cycle arrest and inhibits Wnt/ $\beta$-catenin signaling by reducing cellular $\beta$-catenin level. A) Flow cytometric cell cycle phase analysis in AGS cells upon nimesulide treatment reveals the cell cycle arrest by increasing the G0/G1 phase and reducing $S$ phase cell population. B, C) Nimesulide treatment results in down regulation of E2F (B) and c-Myc (C) transcriptional activity. D) Western blot analysis of cellular $\beta$-catenin and its target genes c-Myc and CyclinD1 in AGS cells \& $\beta$-catenin and CyclinD1 in Kato III cells, upon treatment with nimesulide. E) Analysis of the expression of APC, GSK3 $\beta$ and its phosphorylation (ser9) in the presence of nimesulide in AGS and Kato-III cells by western blotting.

and RXR transcriptional activity. Exogenous PGE2 addition to represent COX-2 pathway activation enhanced the activity of IRF1, STAT3 and RXR in a dose dependent manner (Figure 5A) and moreover these pathways are non responsive to PGE2 in Kato-III cells (Supplementary Figure S2B). This implies that IRF1, STAT3 and RXR pathways are also regulated by the positive regulatory loop of COX-2/PGE2 in gastric cancer which is not identified before. While nimesulide inhibited IRF1 and RXR reporter activity $(P=0.05)$, this inhibition was alleviated or abolished in the presence of PGE2 (Supplementary Figures S2C and S2D). Interestingly, STAT3 activity was inhibited even in the presence of PGE2 $(P=0.03)$ (Figure 5B) and indicates COX2 independency in nimesulide mediated STAT3 inhibition. Inhibition of Wnt signaling in AGS by CTNNB1 knockdown significantly downregulated its downstream c-Myc and E2F1 transcriptional activities $(P=0.03)$ and however, did not alter the IRF1, STAT3 and RXR activities (Figure 5C). All these suggest that nimesulide inhibits IRF1 and RXR through Wnt independent but by COX- 2/PGE2 dependent regulatory mode. Conversely, STAT3 inhibition is mediated irrespective of COX-2 and Wnt $/ \beta$ - catenin signaling. Further, STAT3 itself did not show any influence on IRF1/RXR regulation (Supplementary Figure S2E). 
$\mathbf{A}$

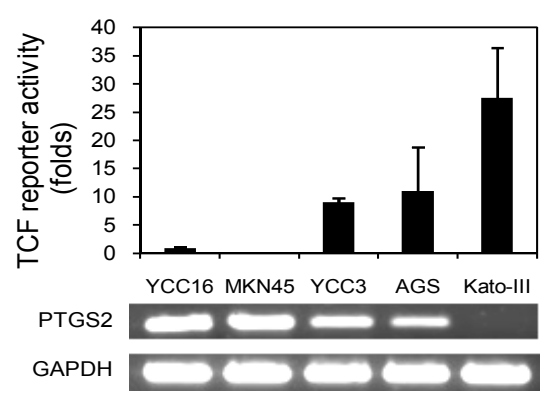

C

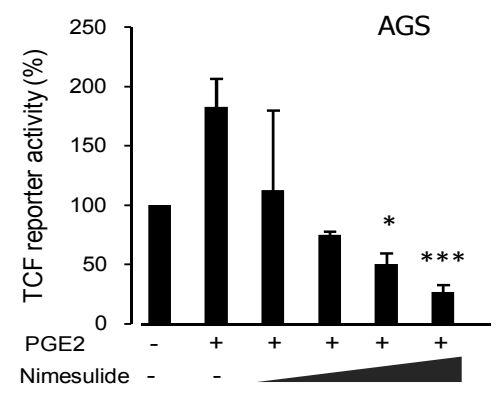

B

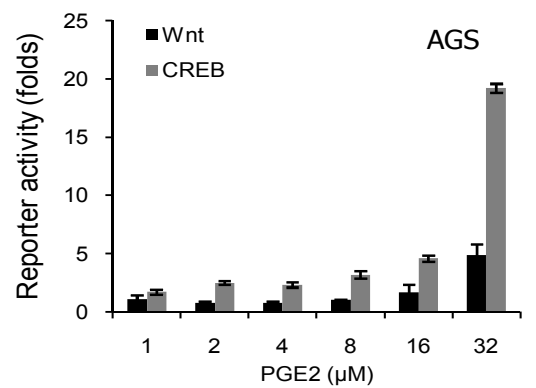

E

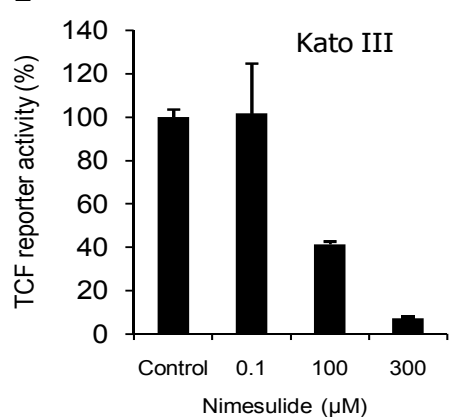

Figure 3: Nimesulide inhibits Wnt/ß-catenin signaling through COX-2 independent mechanism. A) Comparative Wnt signaling activity and PTGS2 (COX-2) expression across gastric cell lines as measured by reporter assay and RT-PCR respectively. B) Reporter assays indicating the positive regulation of Wnt/ 3 -catenin and CREB to PGE2 treatment in AGS cells. C) Dose dependent inhibition of TCF activity by nimesulide in the presence of PGE2 in AGS cells. D) Wnt reporter activity in Kato-III cells upon the treatment of PGE2. E) Inhibition of TCF reporter activity by nimesulide in a dose dependent manner in Kato-III cells (COX-2 negative cell line) indicate COX-2 independency ( $P=<0.05, " ' P=<0.001)$.
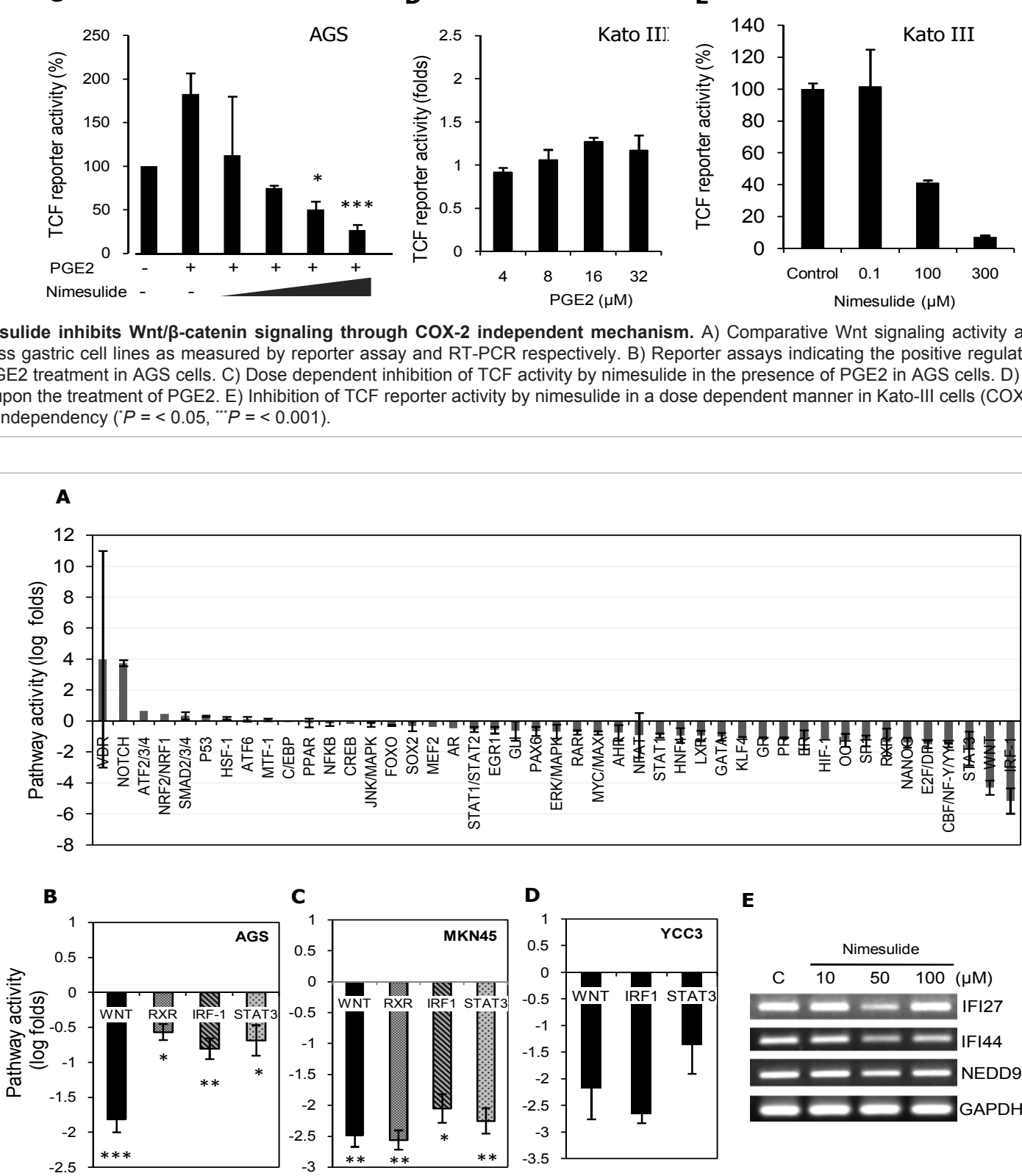

$\mathbf{E}$

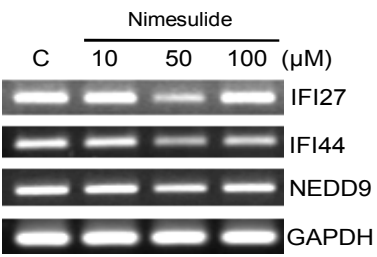

Figure 4: Nimesulide alters the activity of STAT3, RXR and IRF1 signaling in gastric cancer cells. A)Comprehensive screening of nimesulide against 45 signaling pathways by corresponding transcription factor activity reporter assay in AGS cells. B-D) Nimesulide mediated inhibition of Wnt, IRF1, RXR and STAT3 pathways in AGS (B), MKN45 (C) and YCC3 (D) cell lines evaluated by reporter assay. E) RT-PCR showing nimesulide mediated downregulation of the expression of IF127, IFI44, and NEDD9, the target genes of IRF1 and RXR signaling pathways in AGS cells. 

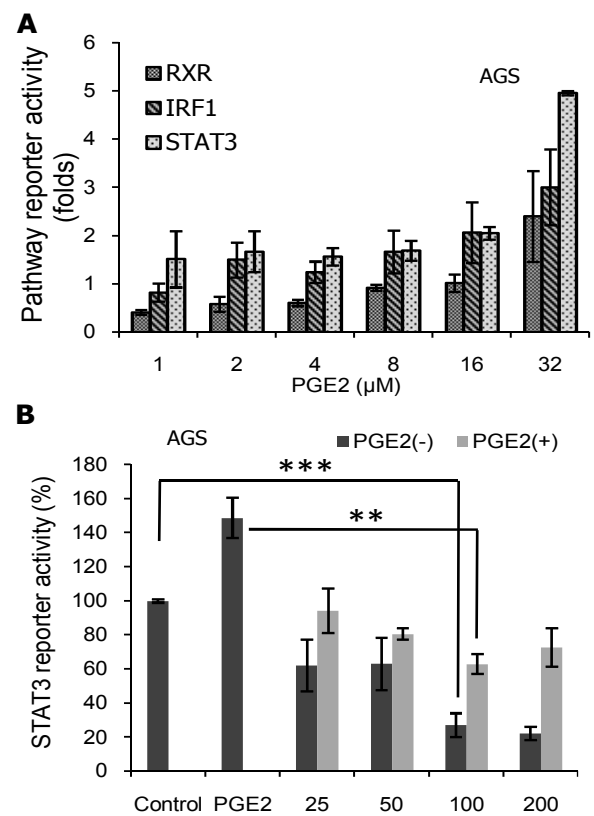

C

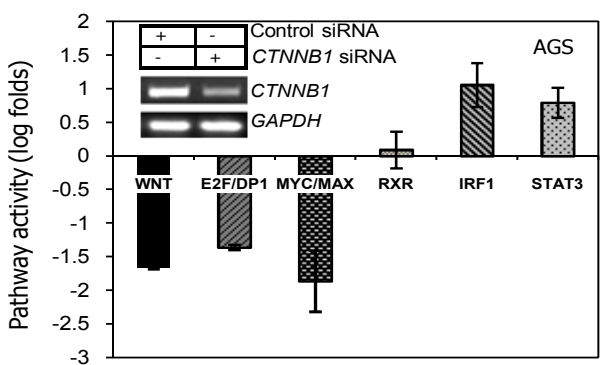

Figure 5: Nimesulide regulates RXR, IRF1 and STAT3 response through COX-2 dependent/independent mechanism. A) Analysis of RXR, IRF1 and STAT3 response upon 12 hours treatment of PGE2 by reporter assay. B) STAT3 pathway is inhibited by nimesulide even in the presence of PGE2 and indicating COX2 independent mode of inhibition. C) Evaluation of Wnt mediated regulation of c-Myc, E2F1, IRF1, RXR and STAT3 activity upon CTNNB1 knockdown followed by reporter assay in AGS cell line. RT-PCR evaluation of CTNNB1 knockdown is shown inside.

\section{Nimesulide and celecoxib shares similar and distinct cellular signaling targets in eliciting anticancer effect}

All the earlier experiments demonstrate nimesulide as a multitarget inhibitor, capable of promoting growth suppression in gastric cancer cells. Though nimesulide inhibits multiple signaling pathways, the activation of Notch is the undesirable event (Figure 3A). A therapeutic candidate having all the beneficial effects of nimesulide without Notch activating features would be more desirable. Upon screening a panel of NSAIDs against Notch signaling in gastric cancer cell lines (data not shown), celecoxib a counterpart of nimesulide was identified with these features. The effect of celecoxib on Wnt $/ \beta$-catenin signaling was not tested in gastric cancer cell lines and hence AGS cells were treated with celecoxib and found to inhibit TCF reporter activity in a dose dependent manner (Figure 6A) and induces cell death (Supplementary Figure S3A). Celecoxib also inhibits the growth of multiple gastric cancer cell lines (Supplementary Figure S3B). Multipathway profiling for the identification of cellular signaling targets of celecoxib using 45 distinct reporter assays identified that pathways which are modulated by nimesulide like Wnt, STAT3, and RXR are also inhibited by Celecoxib at $10 \mu \mathrm{M}$ concentration. Like nimesulide, RXR response was inhibited by celecoxib in a COX-2 dependent manner and STAT3 response through COX-2 independent manner (Supplementary Figures S3C and S3D). Celecoxib also was capable of inhibiting ERK/MAPK pathway reporter activity (Figure 6B). To evaluate the effect of celecoxib on ERK/MAPK response, AGS cells were treated with varying concentrations of celecoxib and the total p42/44 (Erk1/2) and Thr202/Tyr204 phosphorylated p42/44 (Erk1/2) proteins were analyzed. Celecoxib at $40 \mu \mathrm{M}$ concentration markedly reduced the Thr202/Tyr204 phosphorylation of p42/44 (Erk1/2) (Figure 6C). Inhibition of TCF reporter activity by nimesulide and celecoxib were found comparable with existing standard Wnt selective inhibitors PNU-74654 and IWR-1 in AGS cells (Figure 6D). Though nimesulide and celecoxib were known to exhibit chemo preventive effect in experimental animals and patients $[19,34,35]$, the combinatorial effect of these drugs with chemotherapeutic drugs is unclear. To investigate the combinatorial effect with doxorubicin, AGS cells were treated with varying concentrations of doxorubicin along with sub-lethal dose of nimesulide $(100 \mu \mathrm{M})$ or celecoxib $(10 \mu \mathrm{M})$. Cell viability measured at 48 hours after treatment shows that both nimesulide and celecoxib act synergistic with doxorubicin by increasing the cell death while compared to doxorubicin treatment alone (Figure 6E).

Signaling pathways modulated by nimesulide are highly deregulated in primary gastric tumors

While nimesulide and celecoxib inhibits multiple oncogenic signaling pathways in gastric cancer cells, it is worth considering them as possible therapeutic candidates. However, the realistic involvement of the pathways modulated by these drugs in primary gastric tumors is not known and was investigated through integrated transcriptomewide pathway specific gene-set enrichment analysis $[4,27]$ in the mRNA expression profiles obtained from Gene Expression Omnibus (GEO), (GSE15459 and GSE22377) using pathway specific gene signatures obtained from MsigDB or respective publications (Supplementary Table S2). Pathway focused gene signature enrichment analysis in these two different gastric cancer datasets showed higher activation of Wnt (>35\%) pathway followed by Myc, E2F1, STAT3, RXR and Notch in approximately $20 \%$ of gastric tumors and $20-40 \%$ of samples showed interferon- $\beta /$ IRF1 pathway activation (Figures $7 \mathrm{~A}$ and $7 \mathrm{~B}$ ). In multiple combinations, these pathways are activated in intestinal and diffused sub-types of gastric tumors. All these pathways show unique activation pattern along with the co-activation of another pathway(s). This is the first documentation of the activation of IRF1 and RXR signaling pathways in primary gastric tumors. The genes differentially expressed upon nimesulide treatment in a tongue squamous carcinoma cell line, which is available in GEO (GSE15308) (Supplementary Table S3) was investigated over the mRNA expression profiles of primary gastric tumors. The genes inhibited upon nimesulide treatment are indeed overexpressed in primary gastric tumors (Figure 7C and 7D). Moreover, the promoter regions of the genes down regulated upon nimesulide treatment are found enriched with IRF1/2 and PPARG::RXRA binding sites (Figure7E and Supplementary Table S4). This further supports the observation that nimesulide is capable of inhibiting the expression IRF1 and RXR mediated gene regulation, which is prevalently activated in primary gastric tumors.

\section{Discussion}

In gastrointestinal cancers including gastric cancers, $\beta$-catenin is prevalently activated $[7,8]$. Being a major regulator of TCF driven gene expression, $\beta$-catenin is a potential target for the development of inhibitors. Though considerable number of Wnt pathway inhibitors has been identified using cell based high throughput screening and in 
A

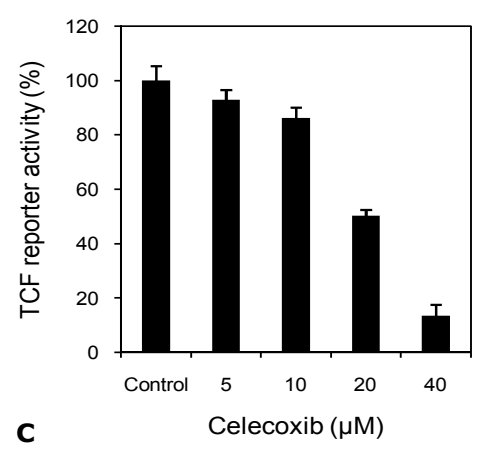

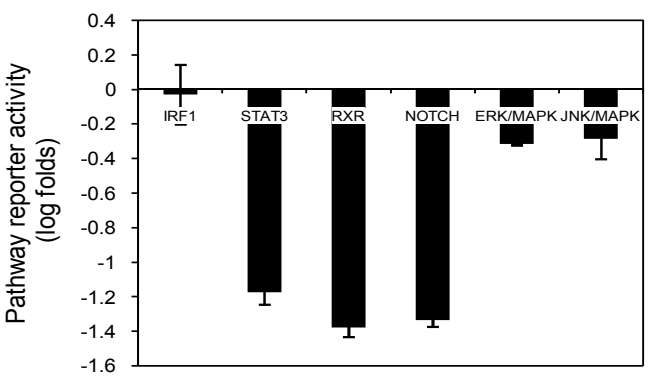

D

\begin{tabular}{|c|c|}
\hline Drugs & IC $_{\mathbf{5 0}}$ (TCF activity) \\
\hline Celecoxib & $20.0 \mu \mathrm{M}$ \\
\hline Nimesulide & $63.5 \mu \mathrm{M}$ \\
\hline PNU-74654 & $25.8 \mu \mathrm{M}$ \\
\hline IWR-1 & $84.0 \mu \mathrm{M}$ \\
\hline
\end{tabular}

$\mathbf{E}$

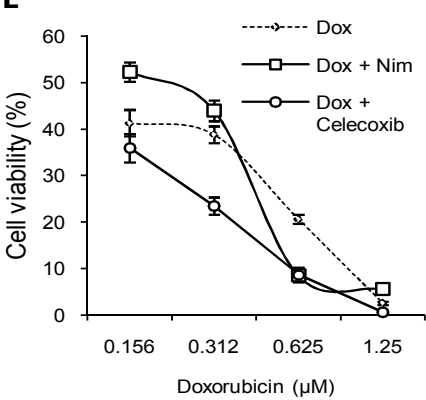

$\mathbf{F}$

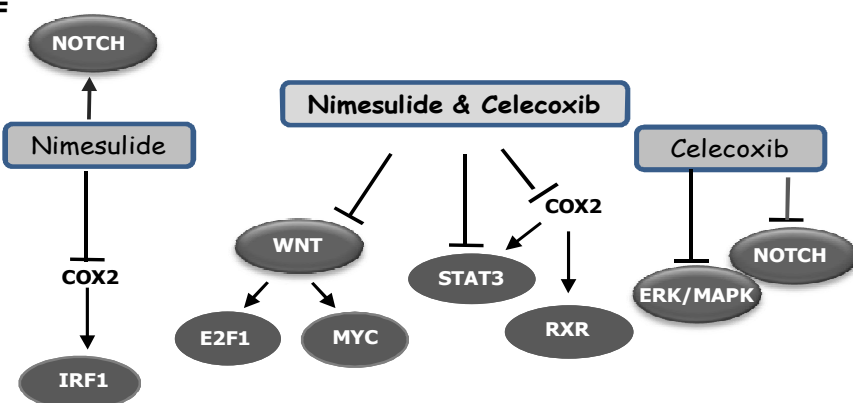

Figure 6: Celecoxib inhibits multiple signaling pathways and improves doxorubicin response in gastric cancer cells. A) Celecoxib inhibits Wnt signaling activity in a dose dependent manner in AGS cells. B) Analysis of IRF1, STAT3, RXR, Notch and MAPK activity in AGS cells upon treating with celecoxib (20 $\mu$ M) for 24 hours. C) Analysis of the effect of celecoxib treatment on ERK/MAPK signaling activity in AGS cells by western blotting. D) Half maximal inhibitory concentrations of TCF reporter activity for celecoxib, nimesulide and other existing Wnt selective inhibitors. E) Analysis of the effect of nimesulide and celecoxib on doxorubicin drug response by MTT assay. F) Summarized schematic representation of the unique and common signaling pathways modulated by nimesulide and celecoxib in gastric cancer cells.

silico biophysical screening [36-38], Wnt pathway based targeted therapy is still lagging behind. The underlying need for Wnt inhibitors is to inhibit the downstream Wnt responsive gene expression which otherwise potentiating cancer progression at various levels. $\mathrm{Wnt} / \beta$ catenin signaling inhibitors acting at the level of $\beta$-catenin would work in any Wnt deregulated cancer cell and can elicit therapeutic effect in wide range of tumors. Therefore, we established a cell based Wnt $\beta$ catenin inhibitor screening system capable of identifying Wnt inhibitors targeting Wnt signaling at the level of $\beta$-catenin or at $\beta$-catenin/TCF transcriptional activation. The gastric cancer cell line employed in this assay harbors a nuclear stabilized $\beta$-catenin which is found in significant proportion of primary gastric tumors [8]. While hunting for new inhibitors, the Wnt inhibitory properties of existing drugs also reported. Wnt pathway inhibitory effect of various nonsteroidal anti-inflammatory drugs (NSAIDs), such as aspirin, celecoxib, sulindac and indomethacin have been identified [20,21,39,40]. From our screen, the Wnt inhibiting effect of nimesulide was identified. The inhibition of TCF responsive activity by nimesulide and celecoxib are comparable with the specific Wnt inhibitors PNU-74654 \& IWR-1. Nimesulide escalates significant cytotoxicity at higher concentrations of above $200 \mu \mathrm{M}$, but elicits potent antiproliferative and Wnt inhibitory effects in the range of 50-100 $\mu \mathrm{M}$ concentration and this indicates the reliable in vitro therapeutic index of nimesulide. It is known that NSAIDs take relatively higher concentrations $(>50 \mu \mathrm{M})$ for their anticancer effects [41]. Nimesulide down regulates oncogenic c-Myc and E2F1 transcriptional activity which also leads to G1-S phase cell cycle arrest and growth inhibition. Inhibition of Wnt signaling by nimesulide is primarily not through COX-2 dependent mechanism. This indicates the existence of additional cellular targets of nimesulide in gastric cancer cells. A search for additional targets of nimesulide (apart from COX-2 and Wnt) at the level of cellular signaling by an unbiased pathway profiling approach has identified the modulation of IRF1, RXR and STAT3 signaling pathways by nimesulide. Among these, inhibition of IRF1 and RXR response by nimesulide is identified for the first time in this investigation. Inhibition of STAT3 and RXR by other NSAIDs like celecoxib, sulindac and etodolac were previously identified [42-45]. Sulindac (Exisulind) with Wnt, STAT3 and RXR inhibiting ability exhibits a promising inhibition of polyp formation in colorectal cancer clinical trials $[46,47]$. Similarly, celecoxib with Wnt and STAT3 inhibiting effects has shown encouraging survival outcome in clinical trials [48], and all these indicate that nimesulide or its derivatives could be potential candidates in targeted gastric cancer therapeutics. IRF-1 and RXR are the regulators of cell growth and proliferation in gastric and other cancers and also the oncogenic face of 
A

200 Gastric tumor samples $\quad$ I Intestinal D Diffused

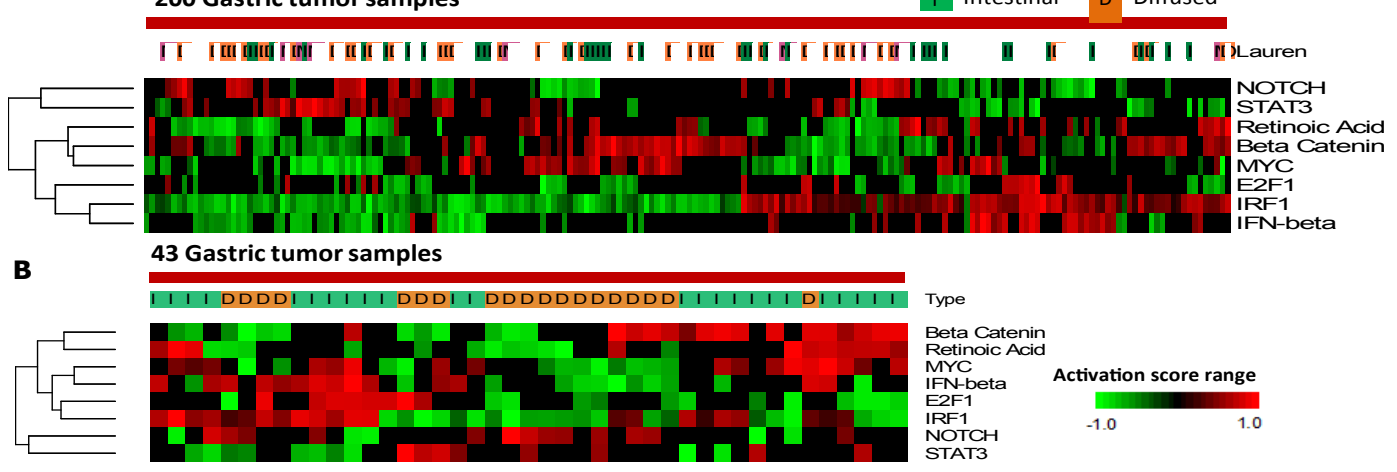

C Normal Tumor

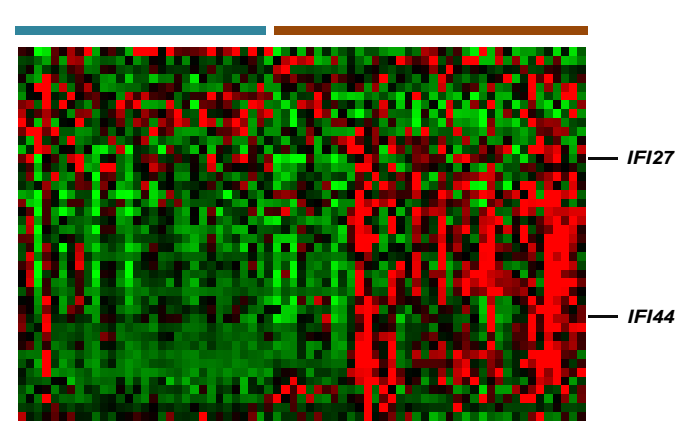

D

$\mathbf{E}$

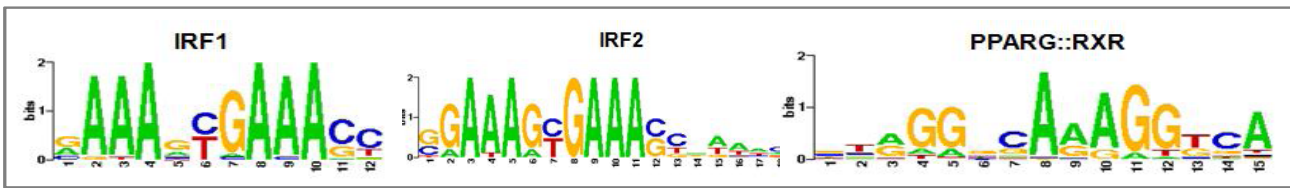

Figure 7: Signaling pathways inhibited by nimesulide and celecoxib are prevalently activated in primary gastric tumors. A, B) Pathway focused gene signature enrichment analysis in two different gastric tumor profiles GSE15459 (A) \& GSE22377 (B) shows the prevalent activation of signaling pathways inhibited by nimesulide and celecoxib across primary gastric tumors. Each row in the heatmap represents the pathway activation scores and column denotes the gastric tumor samples. IRF1 (Interferon- $\beta$ response), Retinoic acid response (RXR), $\beta$ catenin (Wnt), Myc and E2F1 pathways. C,D) The expression pattern of the genes down regulated by nimesulide (obtained by analyzing the gene expression profile GSE15308), in gastric cancer transcriptome profiles GSE13911 (C) \& GSE 17154 (D) reveal their predominant elevated expression in a subset of gastric tumors when compared to normal gastric tissues. E) Over-expression of the IRF target genes IFI27 and IFI44 genes are indicated. E) Transcription factor enrichment analysis using Pscan tool in nimesulide down-regulated genes from GSE15308 profile shows enrichment of IRF1 and RXR regulatory regions in their promoters.

interferon signaling and RXR are also been explained in human lymphocytic and promyelocytic leukemia [49,50]. In addition, gene signature enrichment analysis from our study shows activation of interferon signaling (IRF1) and RXR signaling in independent cohorts of primary gastric tumors and is the first documentation of deregulation in IRF1 and RXR signaling in gastric cancer. Moreover, nimesulide is found capable of inhibiting the expression of genes which are overexpressed in primary gastric tumors. Strikingly, the genes downregulated by nimesulide are enriched with IRF and RXR transcription factor binding sites in addition to NFkB binding sites, which was not identified earlier. Moreover, in vitro assays in our investigation shows that IRF1 and RXR signaling are regulated in the downstream of COX2 whereas; inhibition of STAT3 by nimesulide is a COX-2 independent event (Figure 6F). Accordingly, STAT3 pathway activation pattern is not correlating with Wnt, IRF1 and RXR pathway pattern in primary gastric tumors. On other hand, IRF-1 and RXR signaling enrichment is observed along with Wnt activation in a subset of intestinal type gastric tumors. Another COX-2 inhibitor, celecoxib is identified to possess inhibitory effect on Wnt, STAT3, RXR, Notch, and ERK/MAPK signaling pathways in gastric cancer cells. As previously reported, celecoxib inhibits Wnt and STAT3 signaling. In addition, for the first time, we have identified the inhibition of Notch, RXR and ERK/MAPK signaling upon celecoxib treatment in gastric cancer cell lines. Since MAPK plays very crucial oncogenic role, downregulation of this pathway along with the above mentioned other signaling processes makes gastric cancer cell lines more sensitive to celecoxib. The observation of Notch signaling activation upon nimesulide treatment in gastric cancer cell lines must be carefully studied because of its lineage/context dependent tumor suppressor/oncogenic functions $[51,52]$. Therefore, in the context of Notch signaling modulation, celecoxib could be better therapeutic candidate towards the development of targeted gastric cancer therapeutics. However, the IRF1 signaling inhibition capability observed with nimesulide is not found with celecoxib and this discloses the existence of common and unique cellular targets for nimesulide and celecoxib (Figure 6E). Though, nimesulide being a clinically restricted drug in many countries 
including India for its hepatoxoxicity [53], the recently developed nimesulide analogues were devoid of hepatotoxicity and exhibits promising in vitro and in vivo anti-cancer activity [54]. Hence, the derivatives of nimesulide would be the possible repositioning candidates for targeted gastric cancer therapy, specifically to the tumors with activated identified pathways. This needs to be further investigated. Investigation of the synergistic effect of nimesulide and celecoxib on doxorubicin sensitivity in gastric cancer cell lines identified that nimesulide and celecoxib are capable of enhancing doxorubicin sensitivity. This combinational effect also forecasts the possible utilization of combined nimesulide/celecoxib therapy with selective chemotherapeutic agents such as doxorubicin for gastric cancer. A drug capable of inhibiting multiple oncogenic signaling pathways would be more advantageous and desirable for cancer therapeutics, and both nimesulide and celecoxib possess that capability. However, the target selectivity and specificity slightly varies between nimesulide and celecoxib. Nimesulide and celecoxib were capable of inhibiting Wnt/Myc/E2F, STAT3 and RXR mediated transcription. Nimesulide in addition can inhibit IRF signaling and could activate the Notch signaling. Celecoxib on the other hand could inhibit ERK/MAPK and Notch signaling in gastric cancer cells (Figure 6F). In accordance with MAPK signal inhibition, despite the characteristic higher concentrations of NSAIDS, while the GI50 of nimesulide in AGS cells is $262 \mu \mathrm{M}$ that of celecoxib being $36 \mu \mathrm{M}$ (data not shown). However, the direct involvement of the cumulative and specific signaling targeting in determining the extent of cancer cell growth inhibition needs to be investigated. Thus the current study outlines the beneficial and possible adverse effect of nimesulide and celecoxib through cancer cellular signaling targets and this could be selectively utilized for targeting gastric cancers through genomics guided stratification. In conclusion, we established a cell based Wnt modulator screening system in gastric cancer cell line and identified nimesulide as inhibitor of activated Wnt signaling and various oncogenic signaling pathways. For the first time we report multiple cellular signaling targets of nimesulide and celecoxib and thus provides molecular basis of drug responsiveness. Our study also further reveals Wnt, STAT3, RXR and IRF1 signaling pathways as therapeutically vulnerable targets due to their prevalent activation in gastric cancers and combined targeting of these would elicit a promising therapeutic effect. The identified combinations of signaling inhibition might be the unidentified reason for the clinical and therapeutic effectiveness of various NSAIDs like celecoxib and sulindac. Despite the clinical effectiveness, the molecular targets were not systematically investigated previously. For the first time, a comprehensive panel of signaling driven transcription factor activity profiling has been employed in delineating the molecular targets of a drug. This approach will be certainly useful for the identification of the cellular targets of many drugs and drug candidates in future.

\section{Conflict of Interest}

The authors disclose no potential conflicts of interest.

\section{Acknowledgment}

This work was supported by Department of Atomic Energy (DAE), Govt. of India, through the research grant No.6/6/2008/R\&D-II-230R to Dr. Ganesan Kumaresan, Madurai Kamaraj University. The instrumentation supports by UGCCEGS, DBT-IPLS, UGC-NRCBS, DST-FIST, UGC-CAS and DST-PURSE facilities of School of Biological Sciences, Madurai Kamaraj University are acknowledged. UGC-Meritorious Scholarship to Mr.Jayaprakash Periasamy is acknowledged. The authors thank Dr. Devarajan Karunagaran for his help in providing access to the luminescence reader facility at Indian Institute of Technology Madras.

\section{References}

1. Kamangar F, Dores GM, Anderson WF (2006) Patterns of cancer incidence, mortality, and prevalence across five continents: defining priorities to reduce cancer disparities in different geographic regions of the world. J Clin Oncol 24 2137-2150.

2. American Cancer Society (2011) Global Cancer Facts \& Figures 2nd Edition Atlanta: American Cancer Society.

3. Hanahan D, Weinberg RA (2000) The hallmarks of cancer. Cell 100: 57-70.

4. Ooi CH, Ivanova T, Wu J, Lee M, Tan IB, et al. (2009) Oncogenic pathway combinations predict clinical prognosis in gastric cancer. PLoS Genet 5: e1000676.

5. Tamura G, Maesawa C, Suzuki Y, Tamada H, Satoh M, et al. (1994) Mutations of the APC gene occur during early stages of gastric adenoma development. Cancer Res 54: 1149-1151.

6. Cheng $X X$, Wang ZC, Chen $X Y$, Sun $Y$, Kong QY, et al. (2005) Frequent loss of membranous E-cadherin in gastric cancers: A cross-talk with Wnt in determining the fate of beta-catenin. Clin Exp Metastasis 22: 85-93.

7. Clements WM, Wang J, Sarnaik A, Kim OJ, MacDonald J, et al. (2002) betaCatenin mutation is a frequent cause of Wnt pathway activation in gastric cancer. Cancer Res 62: 3503-3506.

8. Ogasawara N, Tsukamoto T, Mizoshita T, Inada K, Cao X, et al. (2006) Mutations and nuclear accumulation of beta-catenin correlate with intestinal phenotypic expression in human gastric cancer. Histopathology 49: 612-621.

9. Bikkavilli RK, Feigin ME, Malbon CC (2008) G alpha o mediates WNT-JNK signaling through dishevelled 1 and 3, RhoA family members, and MEKK 1 and 4 in mammalian cells. J Cell Sci 121: 234-245

10. Baryawno N, Sveinbjörnsson B, Eksborg S, Chen CS, Kogner P, et al. (2010) Small-molecule inhibitors of phosphatidylinositol 3-kinase/Akt signaling inhibit Wnt/beta-catenin pathway cross-talk and suppress medulloblastoma growth Cancer Res 70: 266-276

11. Kawada M, Seno H, Uenoyama Y, Sawabu T, Kanda N, et al. (2006) Signal transducers and activators of transcription 3 activation is involved in nuclear accumulation of beta-catenin in colorectal cancer. Cancer Res 66: 2913-2917.

12. Noubissi FK, Goswami S, Sanek NA, Kawakami K, Minamoto T, et al. (2009) Wnt signaling stimulates transcriptional outcome of the Hedgehog pathway by stabilizing GLI1 mRNA. Cancer Res 69: 8572-8578.

13. Barker N, Clevers H (2006) Mining the Wnt pathway for cancer therapeutics Nat Rev Drug Discov 5: 997-1014.

14. Garber K (2009) Drugging the Wnt pathway: problems and progress. J Nat Cancer Inst 101: 548-550.

15. Huang SM, Mishina YM, Liu S, Cheung A, Stegmeier F, et al. (2009) Tankyrase inhibition stabilizes axin and antagonizes Wnt signalling. Nature 461: 614-620.

16. Lu D, Choi MY, Yu J, Castro JE, Kipps TJ, et al. (2011) Salinomycin inhibits Wnt signaling and selectively induces apoptosis in chronic lymphocytic leukemia cells. Proc Natl Acad Sci U S A 108: 13253-13257.

17. Leshno M, Moshkowitz M, Arber N (2008) Point/Counterpoint: Aspirin is clinically effective in chemoprevention of colorectal neoplasia: point. Cancer Epidemiol Biomarkers Prev 17: 1558-1561.

18. Wu CY, Wu MS, Kuo KN, Wang CB, Chen YJ, et al. (2010) Effective reduction of gastric cancer risk with regular use of nonsteroidal anti-inflammatory drugs in Helicobacter pylori-infected patients. J Clin Oncol 28: 2952-2957.

19. Phillips RK, Wallace MH, Lynch PM, Hawk E, Gordon GB, et al. (2002) A randomised, double blind, placebo controlled study of celecoxib, a selective cyclooxygenase 2 inhibitor, on duodenal polyposis in familial adenomatous polyposis. Gut 50: $857-860$.

20. Bos CL, Kodach LL, van den Brink GR, Diks SH, van Santen MM, et al. (2006) Effect of aspirin on the Wnt/beta-catenin pathway is mediated via protein phosphatase 2A. Oncogene 25: 6447-6456.

21. Takahashi-Yanaga $F$, Yoshihara $T$, Jingushi $K$, Miwa $Y$, Morimoto $S$, et al. (2008) Celecoxib-induced degradation of T-cell factors-1 and -4 in human colon cancer cells. Biochem Biophys Res Commun 377: 1185-1190.

22. Futagami S, Suzuki K, Hiratsuka T, Shindo T, Hamamoto T, et al. 
Chemopreventive effect of celecoxib in gastric cancer. Inflammopharmacology 15: $1-4$.

23. Liu J, Yu HG, Yu JP, Wang XL, Zhou XD, et al. (2005) Overexpression of cyclooxygenase-2 in gastric cancer correlates with the high abundance of vascular endothelial growth factor-C and lymphatic metastasis. Med Oncol 22 389-397.

24. Shi H, Xu JM, Hu NZ, Xie HJ (2003) Prognostic significance of expression of cyclooxygenase-2 and vascular endothelial growth factor in human gastric carcinoma. World J Gastroenterol 9: 1421-1426.

25. Nuñez F, Bravo S, Cruzat F, Montecino M, De Ferrari GV (2011) Wnt $\beta$-catenin signaling enhances cyclooxygenase-2 (COX2) transcriptional activity in gastric cancer cells. PLoS One 6: e18562.

26. Dyer BW, Ferrer FA, Klinedinst DK, Rodriguez R (2000) A noncommercial dual luciferase enzyme assay system for reporter gene analysis. Anal Biochem 282 : 158-161.

27. Lamb J, Crawford ED, Peck D, Modell JW, Blat IC, et al. (2006) The Connectivity Map: using gene expression signatures to connect small molecules, genes, and disease. Science 313: 1929-1935.

28. Hayakawa Y, Hirata Y, Nakagawa H, Sakamoto K, Hikiba Y, et al. (2011) Apoptosis signal-regulating kinase 1 and cyclin D1 compose a positive feedback loop contributing to tumor growth in gastric cancer. Proc Natl Acad Sci U S A 108: 780-785.

29. Castellone MD, Teramoto H, Williams BO, Druey KM, Gutkind JS (2005) Prostaglandin E2 promotes colon cancer cell growth through a Gs-axin-betacatenin signaling axis. Science 310: 1504-1510.

30. Fujino H, Salvi S, Regan JW (2005) Differential regulation of phosphorylation of the cAMP response element-binding protein after activation of EP2 and EP4 prostanoid receptors by prostaglandin E2. Mol Pharmacol 68: 251-259.

31. Harada H, Taniguchi T, Tanaka N (1998) The role of interferon regulatory factors in the interferon system and cell growth control. Biochimie 80: 641-650.

32. Szanto A, Narkar V, Shen Q, Uray IP, Davies PJ, et al. (2004) Retinoid X receptors: X-ploring their (patho) physiological functions. Cell Death Differ 11 Suppl 2: S126-143.

33. Kim DY, Cha ST, Ahn DH, Kang HY, Kwon Cl, et al. (2009) STAT3 expression in gastric cancer indicates a poor prognosis. J Gastroenterol Hepatol 24: 646651

34. Okajima E, Denda A, Ozono S, Takahama M, Akai H, et al. (1998) Chemopreventive effects of nimesulide, a selective cyclooxygenase-2 inhibitor on the development of rat urinary bladder carcinomas initiated by N-butyl-N-(4hydroxybutyl)nitrosamine. Cancer Res 58: 3028-3031.

35. Fukutake M, Nakatsugi S, Isoi T, Takahashi M, Ohta T, et al. (1998) Suppressive effects of nimesulide, a selective inhibitor of cyclooxygenase-2, on azoxymethane-induced colon carcinogenesis in mice. Carcinogenesis 19: 1939-1942.

36. Lepourcelet M, Chen YN, France DS, Wang H, Crews P, et al. (2004) Smallmolecule antagonists of the oncogenic Tcf/beta-catenin protein complex. Cancer Cell 5: 91-102.

37. Chen B, Dodge ME, Tang W, Lu J, Ma Z, et al. (2009) Small molecule-mediated disruption of Wnt-dependent signaling in tissue regeneration and cancer. Nat Chem Biol 5: 100-107.

38. Trosset JY, Dalvit C, Knapp S, Fasolini M, Veronesi M, et al. (2006) Inhibition of protein-protein interactions: the discovery of drug like beta-catenin inhibitors by combining virtual and biophysical screening. Proteins 64: 60-67.

39. Lee HJ, Wang NX, Shi DL, Zheng JJ (2009) Sulindac inhibits canonical Wnt signaling by blocking the PDZ domain of the protein Dishevelled. Angew Chem Int Ed Engl 48: 6448-6452.

40. Hawcroft G, D'Amico M, Albanese C, Markham AF, Pestell RG, et al. (2002) Indomethacin induces differential expression of beta-catenin, gamma-catenin and T-cell factor target genes in human colorectal cancer cells. Carcinogenesis 23: $107-114$

41. Ulrich CM, Bigler J, Potter JD (2006) Non-steroidal anti-inflammatory drugs for cancer prevention: promise, perils and pharmacogenetics. Nat Rev Cancer 6 : 130-140.

42. Reed S, Li H, Li C, Lin J (2011) Celecoxib inhibits STAT3 phosphorylation and suppresses cell migration and colony forming ability in rhabdomyosarcoma cells. Biochem Biophys Res Commun 407: 450-455.

43. Nikitakis NG, Scheper MA, Papanikolaou VS, Sauk JJ (2009) The oncogenic effects of constitutive Stat3 signaling in salivary gland cancer cells are mediated by survivin and modulated by the NSAID sulindac. Oral Surg Oral Med Oral Pathol Oral Radiol Endod 107: 826-836.

44. Zhou H, Liu W, Su Y, Wei Z, Liu J, et al. (2010) NSAID sulindac and its analog bind RXRalpha and inhibit RXRalpha-dependent AKT signaling. Cancer Cell 17: $560-573$

45. Kolluri SK, Corr M, James SY, Bernasconi M, Lu D, et al. (2005) The $\mathrm{R}$-enantiomer of the nonsteroidal antiinflammatory drug etodolac binds retinoid $\mathrm{X}$ receptor and induces tumor-selective apoptosis. Proc Natl Acad Sci U S A 102: $2525-2530$.

46. Stoner GD, Budd GT, Ganapathi R, DeYoung B, Kresty LA, et al. (1999) Sulindac sulfone induced regression of rectal polyps in patients with familia adenomatous polyposis. Adv Exp Med Biol 470: 45-53.

47. van Stolk R, Stoner G, Hayton WL, Chan K, DeYoung B, et al. (2000) Phase I trial of exisulind (sulindac sulfone, $\mathrm{FGN}-1$ ) as a chemopreventive agent in patients with familial adenomatous polyposis. Clin Cancer Res 6: 78-89.

48. Liao Z, Komaki R, Milas L, Yuan C, Kies M, et al. (2005) A phase I clinical tria of thoracic radiotherapy and concurrent celecoxib for patients with unfavorable performance status inoperable/unresectable non-small cell lung cancer. Clin Cancer Res 11: 3342-3348.

49. Tomic J, Lichty B, Spaner DE (2011) Aberrant interferon-signaling is associated with aggressive chronic lymphocytic leukemia. Blood 117: 2668-2680.

50. Halftermeyer J, Le Bras M, De Thé H (2011) RXR, a key member of the oncogenic complex in acute promyelocytic leukemia. Med Sci (Paris) 27: 973 978.

51. Yeh TS, Wu CW, Hsu KW, Liao WJ, Yang MC, et al. (2009) The activated Notch1 signal pathway is associated with gastric cancer progression through cyclooxygenase-2. Cancer Res 69: 5039-5048.

52. Klinakis A, Lobry C, Abdel-Wahab O, Oh P, Haeno H, et al. (2011) A nove tumour-suppressor function for the Notch pathway in myeloid leukaemia. Nature 473: 230-233

53. Traversa G, Bianchi C, Da Cas R, Abraha I, Menniti-Ippolito F, et al. (2003) Cohort study of hepatotoxicity associated with nimesulide and other nonsteroidal anti-inflammatory drugs. BMJ 327: 18-22.

54. Zhong B, Cai X, Chennamaneni S, Yi X, Liu L, et al. (2012) From COX-2 inhibitor nimesulide to potent anti-cancer agent: synthesis, in vitro, in vivo and pharmacokinetic evaluation. Eur J Med Chem 47: 432-444. 